\title{
THE AMAZING BRAIN
}

\author{
Krikor Dikranian \\ Department of Anatomy and Neurobiology, Washington University School of Medicine, \\ Saint Louis, MO, USA
}

It is in the human nature to be curious about how we feel pain, see the world, hear bird's songs, remember, forget, reason. We want to understand the nature of love, anger, satisfaction, desire and madness. This is a short story about the evolution of the science on the human brain and about major brain discoveries. It gives a concise historic perspective of the understanding of the nervous system - from ancient Egypt to the birth of Renaissance, with the works of Vesalius and his esteemed contemporaries. The contributions of $17^{\text {th }}$ century neuroanatomists such as Tomas Willis followed by the pre-modern neuroscience researchers Camillo Golgi and especially Santiago Ramon y Cajal are highlighted. The contribution of transgenic mouse models and the application of modern noninvasive imaging methods such as positron emission tomography (PET) and magnetic resonance imaging (MRI) for ground braking functional studies on the human brain are briefly reviewed. Important $21^{\text {st }}$ century projects such as the Human and Mouse Connectome projects and the White House Brain Initiative are also presented. Biomed Rev 2015; 26: 1-12.

Key words: psychikon pneuma, census communis, NGF, PET, fMRI, connectome

THE BRAIN is wider than the sky,

... The brain is deeper than the sea, ...The brain is just the weight of God...

Emily Dickinson. Part One: Life. CXXVI

In: Complete Poems, 1924

\section{PREHISTORIC TIMES, ANCIENT EGYPT AND THE GRECO-ROMAN PERIOD}

Evidence suggests that our prehistoric ancestors appreciated that the brain was vital to life. About 7000 years ago people started boring holes in living skulls. Surprisingly many times it was done with the aim not to kill but cure (1). Ancient
Egyptian medicine was a compound of rational, magical and religious elements (2) Soldiers, embalmers and even cooks knew about the brain as a tissue. Open skull fractures allowed Egyptian surgeons to observe the brain, which they called the "the marrow of the skull" or "ais" (3). They had a second word for the brain - "amen", they described hemispheric convolutions and saw the living brain pulsating. However there

Received 10 November 2015, revised 22 November 2015, accepted 23 November 2015.

Correspondence to Krikor Dikranian, MD, PhD, Department of Anatomy and Neurobiology, Washington University School of Medicine, 660 S. Euclid Ave, Saint Louis, MO, 63119, USA. Tel: 314362 3548, Fax: 3143623446

E-mail:kdikrani@pcg.wustl.edu 
is no evidence that a concept of the brain's function has been articulated even if there were words to name this anatomical structure. Egyptians thought so little of the brain that they mostly discarded it when mummifying the body in preparation for eternal life. The heart, not the brain, was considered to be the seat of the soul and the repository of memories. Nevertheless, Egyptian doctors made careful observations of illness and injury $(3,4)$. Recovered papyri indicate that physicians were aware of the symptoms of brain damage. In a patient with an open skull fracture, a surgeon describes the cerebrospinal fluid and meninges. Imhotep was an important figure in ancient Egyptian medicine. He is considered to be the author of the famous "Edwin Smith papyrus"

(1600 B.C.E). This document was buried with its owner in a rock tomb at Thebes. Unearthed in 1862 by grave robbers it was sold to the British egyptologist Edwin Smith. The papyrus is 15 feet long with writings on both sides, it consists of 500 lines of text, contains 48 cases - traumatic head injuries, spinal column injuries and injuries to other parts of the body.

The Greco-Roman world stretches from the first written Greek texts to the fall of the West Roman Empire lasting for almost 1500 years (5). Early Greek anatomists viewed the human brain as an empty shell and the origin of emotions being located in the heart (6). Aristotle (382-322 B.C.E) thought of the brain to be a secondary organ - a cooling agent for the heart and a place where spirits circulated freely. Hippocrates (460-379 B.C.E) saw the brain as the seat of emotion, pain and anxiety, sensation and the seat of intelligence. He wrote ".... it ought to be generally known that the source of our pleasure, merriment, laughter, amusement, as of our grief, pain, anxiety and tears, is none other than the brain. It is specifically the organ, which enables to think, see and hear, and to distinguish the ugly and the beautiful, the bad and the good, pleasant and unpleasant. It is the brain too which is the seat of madness and delirium, of the fears and frights which assail us, often by night, but sometimes even by day..." (4). Erasistratus (304250 B.C.E) was anatomist and royal physician. Along with Herophilus (335-280 B.C.E), he founded a school of anatomy in Alexandria, where they carried out anatomical research. He is credited for his description of the valves of the heart. He also concluded that the heart functioned as a pump, that the arteries were full of air and carried the "animal spirit". Herophilus distinguished between motor and sensory nerves and described several cranial nerves. He identified the meninges and ventricles and recognized the division between cerebellum (paraenkephalis) and cerebrum (enkephalos). He is "the first man to search into the causes of disease" through dissection (7). After Herophilos and Erazistratus there was a rapid decline in Alexandrian anatomical sciences and medicine. Dissection virtually disappears in the west until the rise of medieval universities in the $12^{\text {th }}$ century (4).

Galen was the first physician to produce an accurate description of the anatomy of the brain He discovered three liquid filled ventricles and hypothesized that they were the sites of storage of the vital breath; he assigned the soul and higher cognitive functions in the cerebellum. Galen was born in 129 C.E. in Pergamos. His ethics and his comprehensive works embody the philosophical, scientific, and medical thinking of Greek antiquity and Greco-Roman culture. Galen began his medical studies, at age 17 , as a "therapeutes" at the renowned Asklepieion of Pergamos. From his earliest youth he was familiar with classic reasoning and ideals embodied in the teachings of Hippocrates, Plato and Aristotle. Galen spent some time at Smyrna, Corinth, and Alexandria, where he studied anatomy. At age 30, Galen moved to Rome and built an enviable medical practice $(4,8)$. He also lectured in public amphitheaters and performed animal experiments before lay audiences. He became private physician to the emperor Marcus Aurelius. Galen placed the overseeing soul and its functions, in the "psychikon pneuma" (psychic spirit) in the brain. The heart did play a secondary role: through the carotid arteries, it supplied the brain with the aeriferous blood that contributed to the formation of the psychikon pneuma. Pneuma reaches the brain mixed with arterial blood and via the nostrils. In the brain it is processed into psychikon pneuma, giving rise to thought. It was guided as a signal via the nerves to give rise to the senses and move the voluntary muscles. From this came Galen's idea of ligating or sectioning the nerves to see what impairment(s) resulted, he further wrote "...the brain in man was indeed bipartite. It had a ventricle placed longitudinally on each side ... this third one extended to the so called cerebellum; for the cerebellum was set off by itself, as well as the cerebrum, and was like the jejunum and very much folded. From this the observer may learn that as in those animals that surpass the others in speed of running, such as the stag and hare, well-constructed with muscles and nerves for this, so also, since man greatly surpasses other beings in intelligence, his brain is greatly convoluted".

\section{EUROPE'S DARK AGES, LATE ANTIQUITY AND THE RENAISSANCE}

The historic period following Galen's body of work is 
considered a time when medicine declined and anatomical knowledge was stagnant (9). Scientific curiosity was put on ice only to be thawed by Andreas Vesalius. However starting late antiquity $\left(4^{\text {th }}\right.$ century C.E.) scholars in Europe followed by the Islamic civilization were introducing important changes. All the available Greek and Hellenistic works were translated into Syriac, Hebrew and Arabic. During the $9^{\text {th }}$ century C.E. knowledge of the brain, nerves and senses was brought together in the unified Arabic medical compendia, their Latin versions became standard text at the early European medical schools (10). Physicians in medieval Europe weren't as idle as it may seem, as a new analysis of the oldest-known preserved human dissection in Europe reveals. The specimen consists of a human head and shoulders with the top of the skull and brain removed. The arteries are filled with a red "metal wax" compound that helped preserve the body. During this period the anatomy of the brain consolidated around three principle ventricles. Traditionally imagination was located in the anterior ventricle, memory in the posterior ventricle, and reason located in between. Avicenna (c. 980 -1037), the great Persian physician, philosopher and anatomist wrote that "sensus communis" (common sense) was housed in the "faculty of fantasy", receiving "all the forms which are imprinted on the five senses". Memory preserved what common sense has received. By contrast, the famous medieval anatomist Mondino de' Liuzzi wrote in his Anatomy in 1316 that common sense lay in the middle of the brain. Late antiquity also marks the emergence of Galenism. At the same time the attempt by many scholars and translators to present a succinct account of particular anatomical or medical topics has also contributed to the disappearance of the ambiguities and qualifications expressed by Galen in his original works, replacing their practical and empirical side with the dogmatic. Among other things the Renaissance marks the introduction of anatomical structure into printed books. For centuries, anatomy that had relied solely on textual description and the authority of the written word was transformed.

Leonardo da Vinci was born on the 15th of April 1452. For Leonardo (1452-1519) the study of Anatomy became a science (11-13). He began to examine the relationship between the brain and the olfactory and optical nerves through experimenting with wax injections that helped him to model the ventricles. He sketched the brain from many different perspectives, looking closely at the ventricles and the origins of the nerves from the medulla. Leonardo's images were considerably more anatomical (14). His brain sketch represents a sagittal section through the skull and is influenced by a description by Avicenna. Nothing of the structure of the brain is shown except the ventricles represented as three cavities separated by constrictions and placed in a row, one behind the other. A prolongation of the anterior one extends into the eye and probably represents the optic nerve. The more Leonardo looked, the less he was sure about the function of each ventricle. His goal was to find the location of "sensus communis" but most importantly he tried to locate the seat of soul, as did most of brain investigators at this time. Of the parts of the brain other than the ventricles, he gives little information. Leonardo and later Descartes in the 15th century defined the hydraulic fluid theory of brain function, implying that the cerebrospinal fluid was pumped up through the ventricles producing limbs movements. The last of his written notes reads: "June 24, 1518, Saint John's Day, at Amboise, in the palazzo of Cloux; I shall go on". It is believed that his last spoken words were "I have offended God and mankind because my work did not reach the quality it should have". Charles Estienne (1504-1564) studied medicine in Paris and earned his degree in 1542. Contemporary of Vesalius, began his anatomical book prior to the Fabrica. His principal anatomic work was called "De Dissection Partum Corporis Humani Libri Tres" and was published in 1545 with about 60 woodcuts (14, 15). One of his remarkable observations was the central canal of the spinal cord. In 1561 Estienne became bankrupt and is said to have died in debtor's prison.

At the onset of the $16^{\text {th }}$ century, much more was known about the peripheral nerves than the brain. Galen continued to be influential into the 16th century, when a young and rebellious physician Andreas Vesalius (1514-1564) began the practice of using real human bodies to study anatomy. At age 18, he entered the University of Paris (16). There, professors adhered to the works of Hippocrates and Galen, and thought it below themselves to perform dissections. Young Vesalius and fellow colleagues raided the gallows of Paris for bodies and skeletons to dissect. During one of his anatomical lessons in the medical school, he took the scalpel away from the barber-surgeon, and started dissecting himself. By the age of 22 Vesalius was giving his own dissection centered anatomical lectures. The publication of his De Humani Corporis Fabrica is a monument in the history of science and medicine (Fig. 1). It is almost symbolic that the year Vesalius died at the age of 49 in 1564, the great Galileo was born. Two of the seven books in the Fabrica are dedicated to neuroscience $(13,16)$. Vesalius ridiculed the ventricular doctrine of brain 


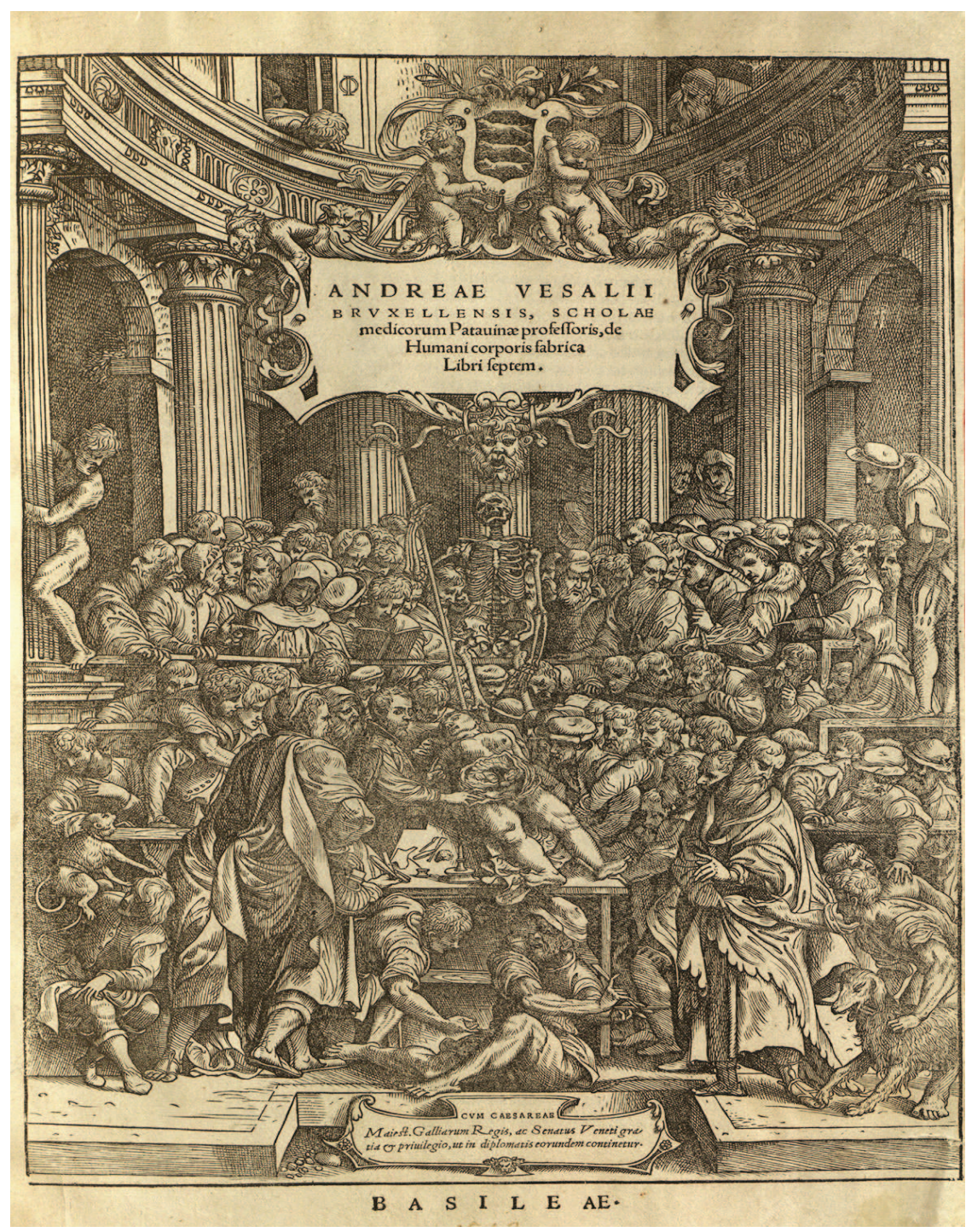

Figure 1. Andreas Vesalius, title page of Humani Corporis Fabrica. Libri Septem, 1543. Vesalius is seen surrounded by representatives of the university, the city, the church, nobility, doctors and student. The bearded man to the right of the central figure of the skeleton is perhaps Dr. Lazarus de Frieis, a friend of Vesalius. Some of the decorations on the top represent the lion of Venice, the ox head of the University of Padua and the monogram of the publisher, Johannes Oporinus. There is still debate about the illustrator of the Fabrica, with speculation that the artist Stephan van Calcar came from the studio of Titian. The publication of this book was a turning point in the history of modern medicine. Washington University Bernard Becker Library, Rare Book Collection, with permission. function. His principle argument against placing the soul in the ventricle was that many animals have ventricles similar to humans and yet they are denied a "soul". He believed the true function of the brain's gyri were to allow blood vessels to bring nutrients to the deeper in brain tissue. One of his brain illustrations shows a horizontal dissection of the human brain (17). Vesalius revered Galen highly but very often his studies of the human form did not fit with Galen's descriptions. These often matched the anatomies of dogs, apes, sheep or other farm animals. He found 200 discrepancies and publicly broke from the Galenic tradition $(14,18)$.

Sixteenth and early seventeenth-century anatomists contributed a great deal to the physical description of the brain but made few significant advances in their understanding of its function (19). Bartolomeo Eustachi (1500-1574) was a brilliant anatomist. In his book "Tabulae Anatomicae" tables 17 and 18 are dedicated to the brain. Eustachi was a contemporary of Andreas Vesalius. He did not embrace Vesalius' reformed anatomy and instead remained a staunch defender of Galen. Eustachi's Galenism did not, however, prevent him from being a skilled and observant anatomist. He is credited with discovering the Eustachian tube and describing the cochlea among other structures. The copperplate engravings he created are remarkable for their clarity and detail. Some of them are more accurate than Vesalius' woodcuts. Unfortunately, the majority were not published until 1714, almost 200 years after Eustachi's death (Fig 2). Varolio (1543-1575) worked in Bologna and then in Rome and served as a personal physician 


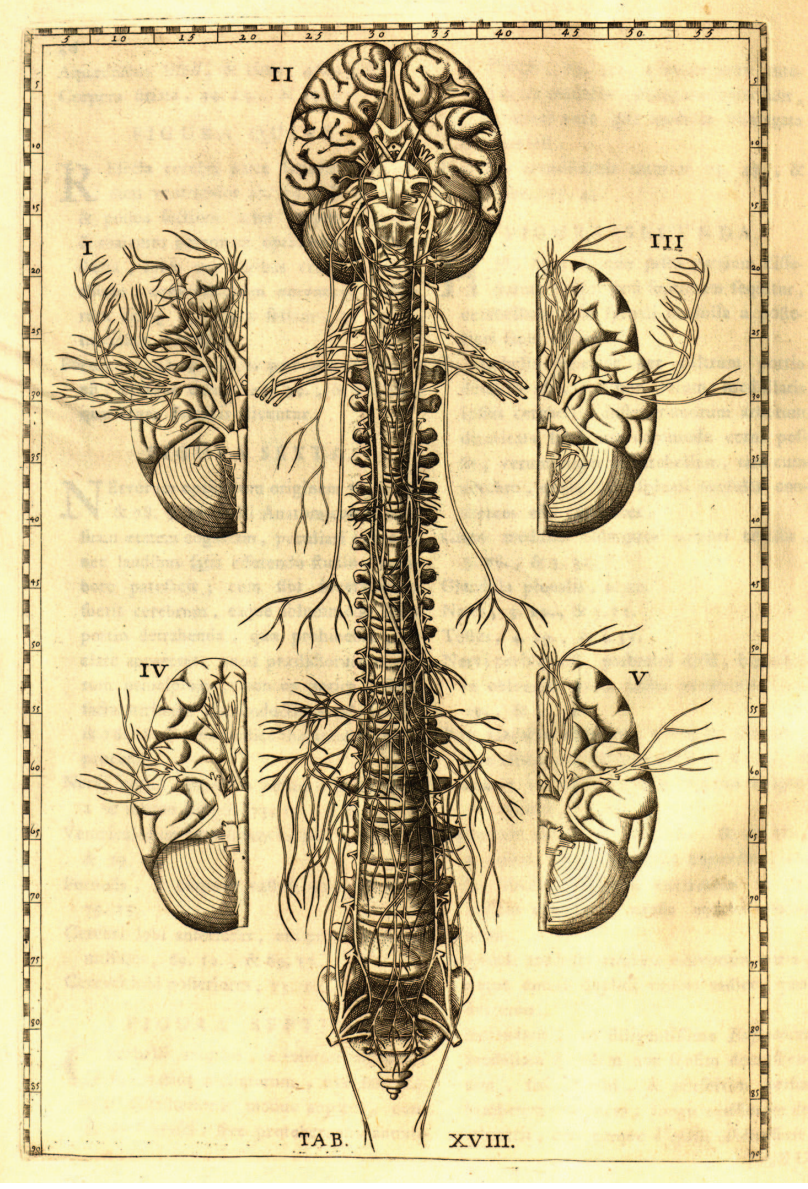

Figure 2. Bartolomeo Eustachi. Tabulae Anatomicae. Plate XVI, Cranial nerves peripheral nerves and plexuses are illustrated, Amstelaedami: Apud R. \& G. Wetstenios, Rome, 1722. Washington University Bernard Becker Library, Rare Book Collection, with permission.

to the pope. He started the examination of the brain from the base and his illustrations show the optic nerves and the chiasm. Not until the 1660s did the anatomy of the brain change significantly. Within a few years of each other, the English physician Thomas Willis published his Anatomy of the Brain in 1664 and the Danish anatomist Nicolaus Steno published his "Lecture on the Anatomy of the Brain" in 1669. Both launched powerful criticisms of Galen's idea of animal spirits which Steno wrote, were "words without any meaning." He further argued for a more careful exploration of the cortex and the ventricles, writing about sensus communis: "that beautifully arched cavity does not exist." Willis brought this point further home by arguing that the ventricles were not formed as part of God's design to house the spirits but "accidentally from the complication of the brain." Given that, "the supreme seat of the Soul" could hardly be there. Nor could it be in the pineal gland, as Descartes had proposed.

Tomas Willis (1621-1675) was born on 27 January 1621 in Wiltshire, England. Young Thomas was educated in Oxford. He obtained his medical degree in 1646. He became a member of an informal group of experimental scientists "The Virtuosi" who, together with the Virtuosi of London were the forerunners of the Royal Society. He was professor of natural philosophy at Oxford in 1660 and, on moving to London in 1666, acquired the largest fashionable practice of his day. Dr. Willis performed necropsies on his patients and made extensive anatomic dissections on the brain. In his images the anatomy of brain convolutions, sulci a fissures are much more clearly defined than Vesalius. His co-workers included the physicists Robert Hooke and Robert Boyle, Richard Lower, an anatomist, physiologist, and clinician, who administered the first blood transfusion, and Sir Christopher Wren, the renowned architect (of Saint Pauls' cathedral in London) and artist who was responsible for the engraved plates from which the illustrations are derived in his book Cerebri Anatome Nervorum Descriptio et Usus published in 1664 in Oxford $(13,14)$ (Fig. 3). This work included Willis's classification of the cranial nerves and his description of the arterial pattern at the base of the brain - the circle of Willis. His most important contribution, a discussion of cerebral circulation, was based on ingenious use of india ink injections and inspired by Harvey's ideas of the circulation of the blood. He emphasized the capability for collateral circulation if an artery becomes blocked. He comments on the dissection he made of a patient who has died of abdominal illness: "When his skull was opened we noted amongst the usual intracranial findings, the right carotid artery, in its intracranial part, bony or even hard, its lumen being almost totally occluded; so that the influx of the blood being denied by this route, it seemed remarkable that this person had not died previously of an apoplexy: which indeed he was so far from, that he enjoyed to the last moments of his life, the free exercise of his mental and bodily functions. For indeed, nature had provided a sufficient remedy against the risk of apoplexy in the vertebral artery of the same side in which the carotid was wanting, since the size of this vessel was enlarged, becoming thrice that of the contralateral vessel." (14). Willis thought that the cerebral cortex covered many subcortical centers, that cortical gray matter was responsible for animal spirits, while the white matter distributed the spirits to the body, governing movement 


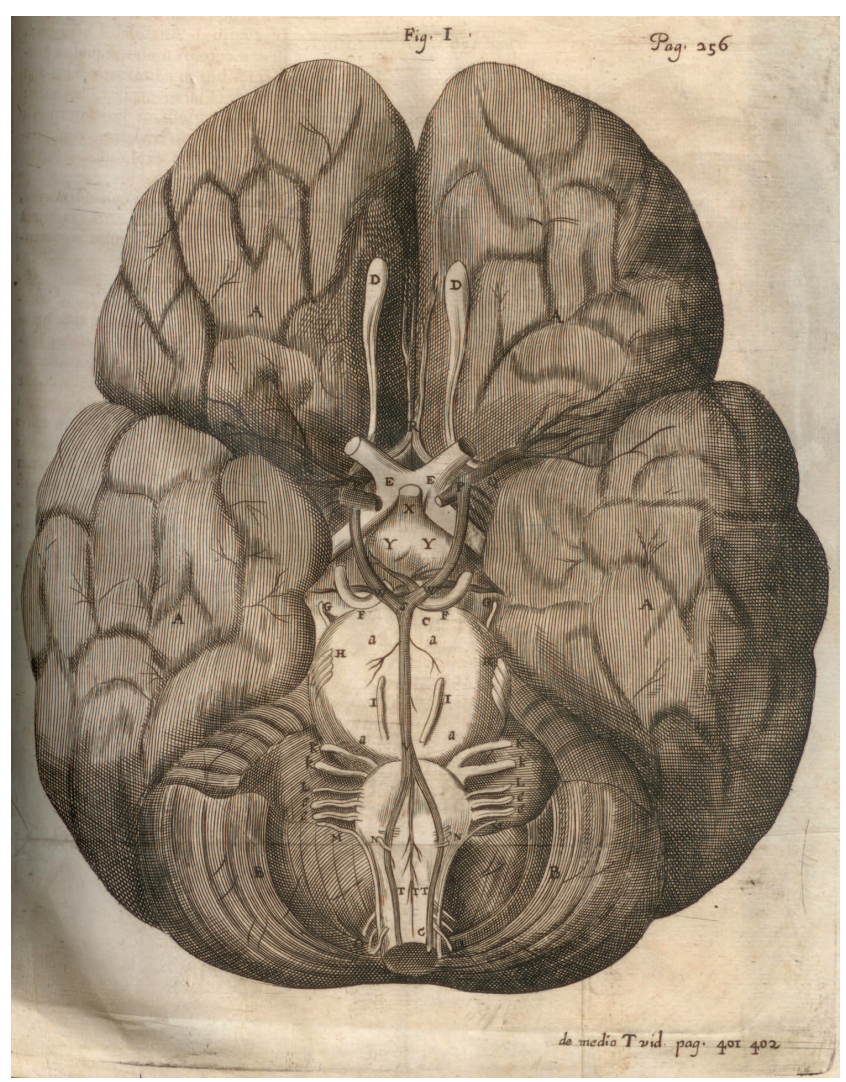

Figure 3. Tomas Willis (1621-1675). Cerebri Anatome: Cui Accessit, Nervorum Descriptio Et Usus, page 256. This volume of "The Anatomy of the Brain" was published in London in 1664 and was translated from Latin to English a few years later. The original illustrations were made by Sir. Christopher Wren. The brain was approached from below and removed from the skull before being dissected. In this image the famous "circle of Willis", a collateral arterial network at the base of the brain, is illustrated. Washington University Bernard Becker Library, Rare Book Collection, with permission.

and sensation. He implicated the "cortical and grey part of the cerebellum" in the functions of memory and movements. The cortex initiates voluntary movements whereas the cerebellum is involved only in involuntary movements. These statements were obviously supported not only by his dissections, but also from his experiments on animals and from analyzing his patients. Interestingly, despite the importance of the cortex for Dr. Willis, his work contains no separate drawing of the cortex; he apparently never asked Wren or anybody in his team to produce one. For the next 150 years the cortex will be drawn as Erasistratus suggested: as coils of the small intestine. Willis died in London at age 54 and was buried in Westminster Abbey.

\section{THE CAJAL ERA AND ITS FAMOUS CONTEMPORARIES}

Camillo Golgi (1843-1926) graduated medicine in 1865 at the University of Pavia (20). He believed that mental diseases could be due to organic lesions of the neural centers. In 1872 financial problems forced him to interrupt his academic career and he accepted the post of chief resident physician to the Hospital for the chronically ill in a small town near Milano and Pavia. Here in his kitchen, made into a rudimentary laboratory, working mainly at night by candlelight, he discovered in 1873 a silver chromate method for staining nerve tissue, the so-called black reaction "la reazione nera". In 1881 he was appointed to the chair of General Pathology at the University of Pavia. In the minds of most neuroscientists the name of Camillo Golgi is associated with the theory that nerve cells communicate with one another by means of an intricate network of anastomosing axonal branches contained (13). In 1875 Golgi published, in an article on the olfactory bulbs, the first drawings of neural structures as visualized by this technique. The discoveries of Golgi led Wilhelm von Waldeyer-Hartz to postulate in 1891 that the nerve cell is the basic structural unit of the nervous system, which is a critical point in the development of modern neurology. In 1906 Golgi shared the Nobel Prize with Santiago Ramón y Cajal "in recognition of their work on the structure of the nervous system". He remained as professor emeritus at the University of Pavia until his death in 1926.

Santiago Ramón y Cajal (1852-1934) took his Licentiate in Medicine at Saragossa in 1873 and as an army doctor took part in an expedition to Cuba in 1874-75. Back in Spain he became an assistant in the School of Anatomy in the Faculty of Medicine at Saragossa and then, at his own request, Director of the Saragossa Museum. In 1883 he was appointed Professor of Descriptive and General Anatomy at Valencia. In 1887 he was appointed Professor of Histology and Pathological Anatomy at Barcelona and in 1892 he was appointed to the same Chair at Madrid. In 1900-1901 he was appointed Director of the «Instituto Nacional de Higiene». Cajal was a painter, artist, and gymnast. Applying the Golgi stain with virtuoso's dexterity, he presented the world for the first time with visible populations of individual neurons, Santiago Ramòn y Cajal wrote the Neuron Theory in 1887 (21) It is considered to be one of the principle conquests of the $20^{\text {th }}$ century. The formulation of the Neuron doctrine was achieved between 1888 and 1889. In fact Cajal admits that 1888 is his "fortunate year', he is then 
at the University of Barcelona. When Cajal began his studies the reticular theory, supported by Golgi was the prevailing theory among the scientific community. Cajal was the first to provide fundamental scientific data by publishing his studies on basket cells of the cerebellum of birds, which establish nest-like terminals around the body of a Purkije cell. In 1888 he publishes another paper on the parallel and climbing fibers terminating freely on the dendrites of Purkinje cells. In his words "... having arrived at the level of the first arms of the mentioned dendritic stems, they split up into snaking parallel plexuses that ascend all along the protoplasmic branches, hugging their form, like ivy or lianas that cling to the trunks". He thus proves that there is in fact contiguity but not continuity among nerve terminals. He establishes that "the nerve cells are independent elements that are never anastomosed" and "nervous propagation is verified by contacts at the level of certain apparatus or cogs devices". In 1906 he shared the Nobel Prize with Camillo Golgi. Before the decision there had been some severe controversies between the two scientists on the one hand, and the members of the jury on the other hand, because Golgi's discovery was older, and because the works of Ramon y Cajal were so dependent on that of Golgi, without which Ramon y Cajal would probably never have arrived at his results. However, many consider Ramón y Cajal the greater of the two. Golgi described their relationship as that of "two Siamese brothers attached to the back".

\section{RITA LEVI-MONATALCINI AND NGF: THE "GROWTH FACTOR" ERA OF NEUROBIOLOGY}

The first cell growth factor, nerve growth factor (NGF), was discovered by Rita Levi-Montalcini in the early 1950's in Washington University in Saint Louis, Missouri, USA (reviewed in 22). Originally identified as neurite outgrowthstimulating factor, later studies revealed that non-neuronal cells, including immune cells, endothelial cells, cardiomyocytes, pancreatic beta cells, testicular Leydig cells, prostate epithelial cells and adipose tissue cells, are also targets for and/or sources of NGF. Nerve growth factor is well recognized at present to mediate multiple biological phenomena, ranging from the neurotrophic through immunotrophic and epitheliotrophic to metabotrophic effects. Consequently, NGF and other members of the neurotrophin family (pro-NGF, brain-derived neurotrophic factor, neurotrophin-3, -4/5, -6) are implicated in the pathogenesis of a large number of neurological and nonneurological diseases, ranging from Alzheimer's and other neurodegenerative diseases to ocular, cutaneous, cancer, and cardiometabolic diseases such as atherosclerosis, obesity, type 2 diabetes, metabolic syndrome (23).

\section{THE BRAIN FUNCTION AND ITS MAPS}

The very first to describe the structure of a human brain in regard to its integral function and pathways were Pierre Broca, Carl Wernicke, who analyzed the effect of the different localization of the brain lesions over the limbs motility and speech function.

Pierre Paul Broca (1824-1880) provided compelling evidence for the concept of "localization of function," which holds that different parts of the brain do different things (24). In 1861 Dr. Broca encountered two patients. One was an epileptic man named Leborgne known as "Tan" nicknamed after the only syllable he was capable of uttering (25). He was able to understand spoken language but couldn't articulate his thoughts in speech - something that perplexed Broca enormously, given that one of Leborgne's first symptoms was a weakening of function in the right side of his body, which progressed to more loss of motor control and eventually the loss of sight and some of his mental faculties. When Leborgne died, Broca dissected his brain and found a massive lesion in the left frontal cortex and concluded that this must somehow be related to the loss of speech. Then came Lelong, who after a fall was only able to utter a few words. When Lelong died, Broca discovered a similarly dramatic lesion in the left side of his brain. Broca also coined the term "Limbic lobe" which is related to emotions and emotional expression. After Broca published his findings damage-related language deficits, Carl Wernicke (1848-1905) researched the effects of brain disease on speech and language. He discovered that not all language deficits were the result of damage to Broca's area. Damage to the left posterior, superior temporal gyrus resulted in deficits in language comprehension. This region is now referred to as Wernicke's area, and the associated syndrome is known as receptive aphasia. Korbinian Brodmann's (1868-1918) integrated evolutionary ideas and histological analysis of the cortex with functional localization $(13,26)$. He studied the cytoarchiteacture of more than 52 areas in the human brain, a huge body of work which he did in the Neurobiologisches Laboratorium in Berlin and published his results in a 1909 monograph "Localization in the cerebral Cortex". Brodmann defined these functional areas distinguished by their different cellular organization and neuronal populations. Thus, several functional cortical areas such as primary motor cortex, premotor cortex, sensory 
cortex and visual cortex have been identified, each having their morphologic particularities (27). Wilder Penfield (18911976) graduated Oxford University in 1916 and his exposure to Dr. Charles Sherrington inspired him to study the nervous system (28). He completed his medical degree at John Hopkins School of Medicine and later became a neurosurgeon. As a surgical intern in Peter Bent Brigham Hospital in Boston he was inspired by Prof. Cushing's surgical techniques. Working with a succession of neurosurgical associates, performing groundbreaking surgeries for epilepsy, he studied the responses of the human cerebral cortex to electrical stimulation. He characterized topographical distribution of the primary and secondary sensory and motor areas, the representation of language function in the inferior frontal, superior frontal and temporo-parietal cortex. He defined the role of the hippocampi and the lateral temporal cortex in memory.

\section{AND XXI CENTURY ADVANCES IN NONINVASIVE BRAIN RESEARCH}

In 1971, Godfrey Hounsfield first introduced X-ray computed tomography (CT) in London. He created 3-dimensional transaxial tomographic images of an intact object with data arising from a large number of projections through the object. Hounsfield's invention literally changed the practice of medicine. He and Alan Cormack, received the 1979 Nobel Prize for Physiology or Medicine. Although these noninvasive imaging techniques were very informative about the central nervous system, information on the brain function was to be the province of Positron Emission Tomography (PET) and Magnetic Resonance Imaging (MRI)(29, 30). PET works by detecting gamma rays so as to allow the site of radioactive decay using "tomographic" methods analogous to those used for CAT scans. PET can be used as a quantitative probe for a broad range of metabolic, biochemical, and pharmacological measurements. It is used to study brain activity and also to reveal mechanisms of "neurovascular coupling" - the relationship between electrical brain activity and the vascular responses observed by PET and MRI. PET derives its name and fundamental properties from a group of radionuclides $\left({ }^{15} \mathrm{O},{ }^{11} \mathrm{C},{ }^{18} \mathrm{~F}\right.$ and $\left.{ }^{13} \mathrm{~N}\right)$ with short half-lives, a unique decay scheme, and chemical properties. The first cyclotron dedicated to biomedical research and radiation therapy was installed at the Hammersmith Hospital in London. A second cyclotron was installed at the Mallinckrodt Institute of Radiology of the Washington University School of Medicine. Michel Ter-Pogossian will be remembered as the "father of PET."
Ter-Pogossianhe came to the United States in 1946. He was drawn to Washington University Department of Physics by the reputation of Arthur Holly Compton (a physicist and a Nobel laureate) and worked as research assistant. He joined the faculty of Mallinckrodt Institute in 1950 and was appointed Professor of radiation sciences in 1961. In 1973 as a head of Mallinckrodt Institute's Division of Radiation Sciences and together with his team of physical scientists, chemists, and physicians - Drs Phelps, Cox and Donald developed the concept and the design of the first PET scanner.

MRI has better resolution in space and time compared to PET, and offers a wide range of scan types that are informative about brain structure, function, and connectivity. Mechanistically, MRI involves complex quantum-mechanical phenomena. Protons (hydrogen atoms, mainly in water molecules) act like tiny magnets that are aligned to the strong magnetic field of the scanner. These protons can be transiently knocked out of alignment by brief radio frequency 'pulses' generated by the scanner. As the protons gradually realign to the main magnetic field ('relax'), they emit faint radio frequency signals detected by sensitive electrical receivers within the scanner. These signals are reconstructed to form images whose appearance depends upon the particulars of the pulse sequence as well as the individual brain being scanned (Fig. 4A).

Over the past two decades, there have been dramatic advances in the methods of acquisition, analysis, and visualization of MRI data such as functional MRI (fMRI), and diffusion MRI (dMRI). Structural MRI enables highresolution visualization of cortical and subcortical structures in individual subjects. Structural MRI pulse sequences reveal contrast based on tissue type (e.g., gray vs white matter). They include 'T1-weighted' (T1w) and 'T2-weighted' (T2w) scans. Functional MRI relies on the Blood Oxygenation Level Dependent (BOLD) contrast mechanism. Brain electrical leads to increased blood flow and hence elevated oxyhemoglobin levels relative to what is metabolically required by the active tissue. Because oxyhemoglobin and deoxyhemoglobin have different magnetic properties, regions of increased oxyhemoglobin (higher activity) can be differentiated from those with higher deoxyhemoglobin (lower activity) using appropriate MRI pulse sequences - a T2* scan. BOLD signal likely reflects local synaptic as well as neuronal action potentials. FMRI has greater sensitivity and higher resolution in both space and time. The brain is always active (even when not doing an overt task, and even while asleep), and this is 

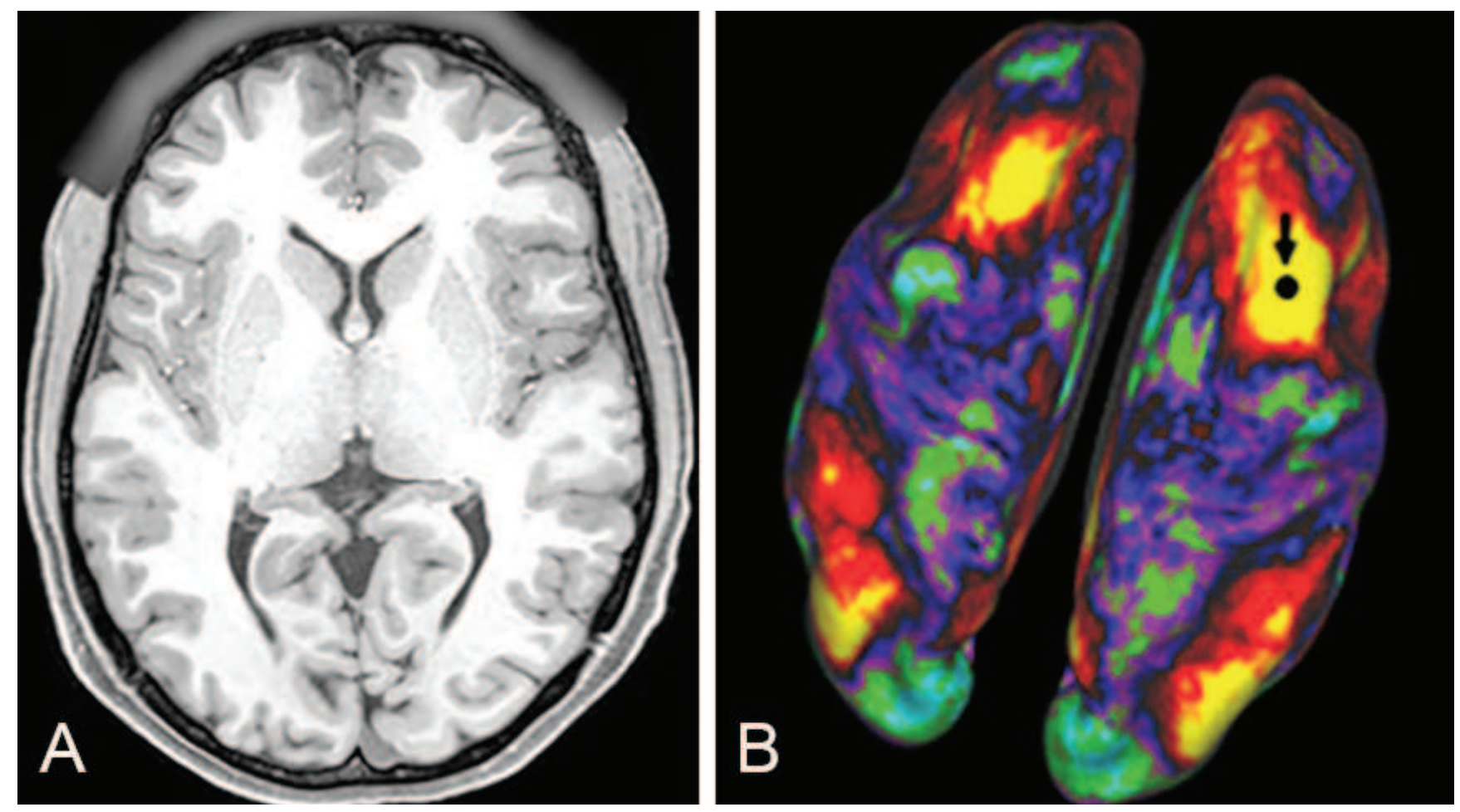

Figure 4. A. High resolution axial slice from the brain volume of an individual Human Connectome Project (HCP) subject obtained with structural MRI, showing the high resolution of the imaging data being collected. Image courtesy of the HCP consortium - http://humanconnectome.org. B. Functional Connectivity: A map of the average "functional connectivity" in the human cerebral cortex collected on healthy subjects while "at rest" in the MRI scanner. Regions in yellow/red are functionally connected to the "seed" location in the right frontal cortex (black circle, arrow), whereas regions in green and blue are weakly connected or not connected at all. Image courtesy M. F. Glasser and S. M. Smith for the HCP consortium.

reflected in spontaneous fluctuations in the BOLD signal that exceed the modulation caused by specific tasks. The spontaneous BOLD fluctuations are not random, but tend to be correlated in time with the fluctuations at many other locations, both nearby and at long distances. The pattern of strong rfMRI correlations is similar to the pattern of strong anatomical connectivity - the correlation patterns are often referred to as 'functional connectivity' even though they are imperfect surrogate for genuine anatomical connectivity (Fig. 4B). TaskfMRI typically reveals a spatially complex pattern of activation and deactivation when comparing different tasks. Multiple cortical areas are activated by any given task or task contrast; different tasks may show overlapping activation patterns. The brain contains spatially distributed networks and subnetworks serving diverse brain functions. Diffusion MRI (dMRI) uses pulse sequences that are sensitive to the rate at which molecules diffuse in different directions. Because diffusion is faster along the length of axons compared to transversely, across axonal and myelin membranes, dMRI reveals the orientation of fiber bundles in regions where they course in parallel (Fig. 5A). Tractography is a method for estimating the long-distance trajectories of major pathways (Fig. 5B).

\section{THE MOUSE AND THE HUMAN CONNECTOMES}

Understanding how the precise interconnections of neurons account for brain functions has been a preoccupation of neuroscientists for over a century. Conceptually, a "connectome" is a "comprehensive" map of neural connectivity. Neuroscientists have used three main sets of anatomical approaches to study neural connectivity in experimental animals, predominantly mice and primates: single-cell impregnation, optically based tract-tracing and later electron 

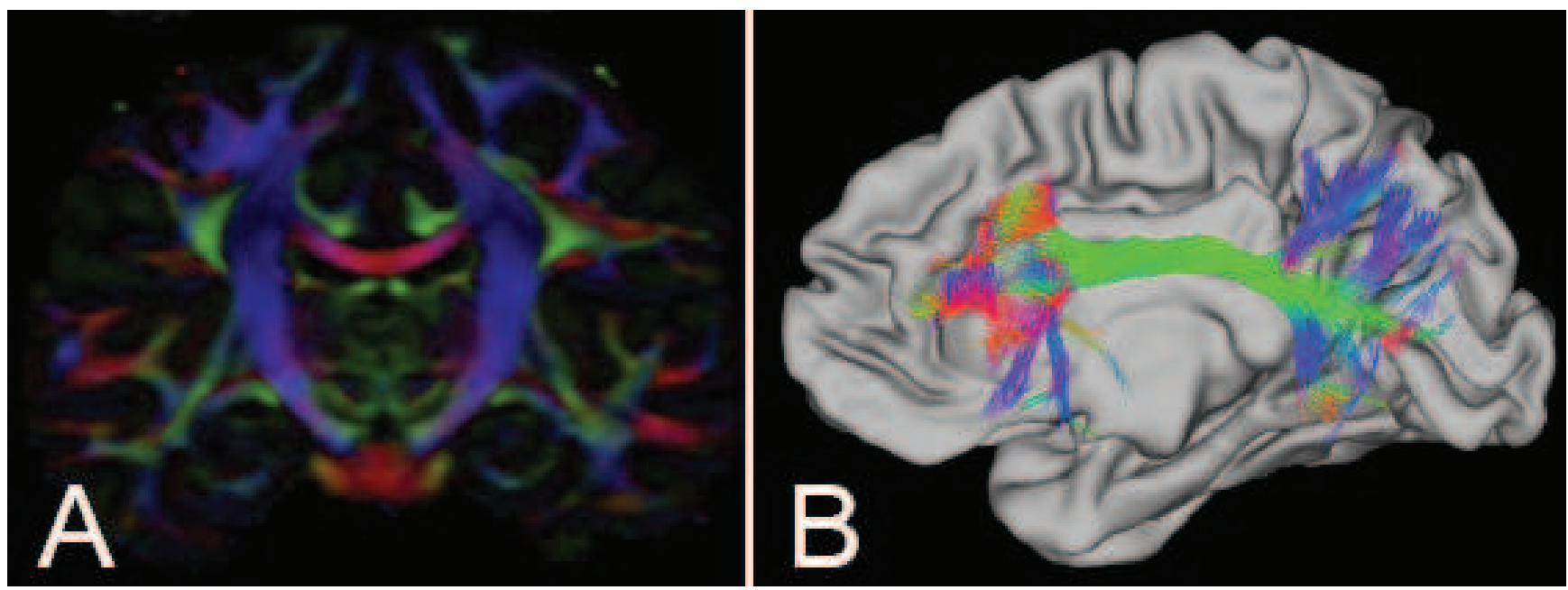

Figure 5. A. Diffusion Fractional Anisotropy. Principal diffusion directions images from the Human Connectome Project (HCP) dMRI data provide a measure of how water diffuses in the brain. Diffusion directions are RGB-color encoded - red: left-right, green: anterior-posterior, blue: inferior-superior. Image courtesy of the HCP consortium - http://humanconnectome.org. B. Structural Connectivity: 3D probabilistic trajectories of white matter fibers arising from a seed in the left frontal cortex. The orientation vectors at each voxel are RGB color-coded coded (red: Left-right, green: anterior posterior, blue: inferior-superior). Image courtesy S. Sotiropoulos and T. E. J. Behrens for the HCP consortium.

microscopy. Serial section electron microscopy has been the method of choice for overcoming the limited resolution of light microscopy and the insufficiencies of tract-tracing. Nonetheless, large-scale reconstruction, especially over long distances, remains a distant hope. The green fluorescent protein (GFP) revolution has led to a technical renaissance in brain imaging. The so-called "Brainbow" transgenic mice were engineered in Dr. Jeff Lichtman's and Dr. Joshua Sane's lab $(31,32)$. The role of Brainbow mice in connectomics was huge. It not only generated strikingly beautiful images but contributed to the discovery and mapping of many brain neuronal circuits. Dr. Lichtman went further using serial electron microscopy to reconstruct various axonal processes, their synapses on dendrites and their spines.

For the living human brain, connectivity can only be estimated for the 'macro-connectome', using noninvasive neuroimaging. MRI provides two complementary methods for inferring connectivity. Diffusion MRI is used to infer structural connectivity, and resting-state fMRI is used to infer functional connectivity. The Human Connectome Project (HCP) is an effort centered at Washington University School of Medicine in Saint Louis and University of Minnesota Medical School to study brain circuits in a large population of healthy
12000 adults. Its primary goal is to delineate the typical patterns of structural and functional connectivity in the healthy adult human brain (31). HCP is also using task-fMRI to help delineate the relationships between individual differences in the neurobiological substrates of mental processing and both functional and structural connectivity. The results from the HCP will be published in the public domain and will offer a critical stepping-off point for future studies that will examine how variation in human structural and functional connectivity play a role in neurological and psychiatric disorders. The Human Connectome Project is collecting behavioral measures of a range of motor, sensory, cognitive and emotional processes that will delineate a core set of functions relevant to understanding the relationship between brain connectivity and human behavior Altogether, the HCP will lead to major advances in our understanding of what makes us uniquely human and will set the stage for future studies of abnormal brain circuits in many neurological and psychiatric disorders (Fig. 6).

\section{THE BRAIN INITIATIVE}

The Brain Research through Advancing Innovative Neurotechnologies (BRAIN) initiative was announced in 2013 by the White House. This multiagency Initiative is led by the 


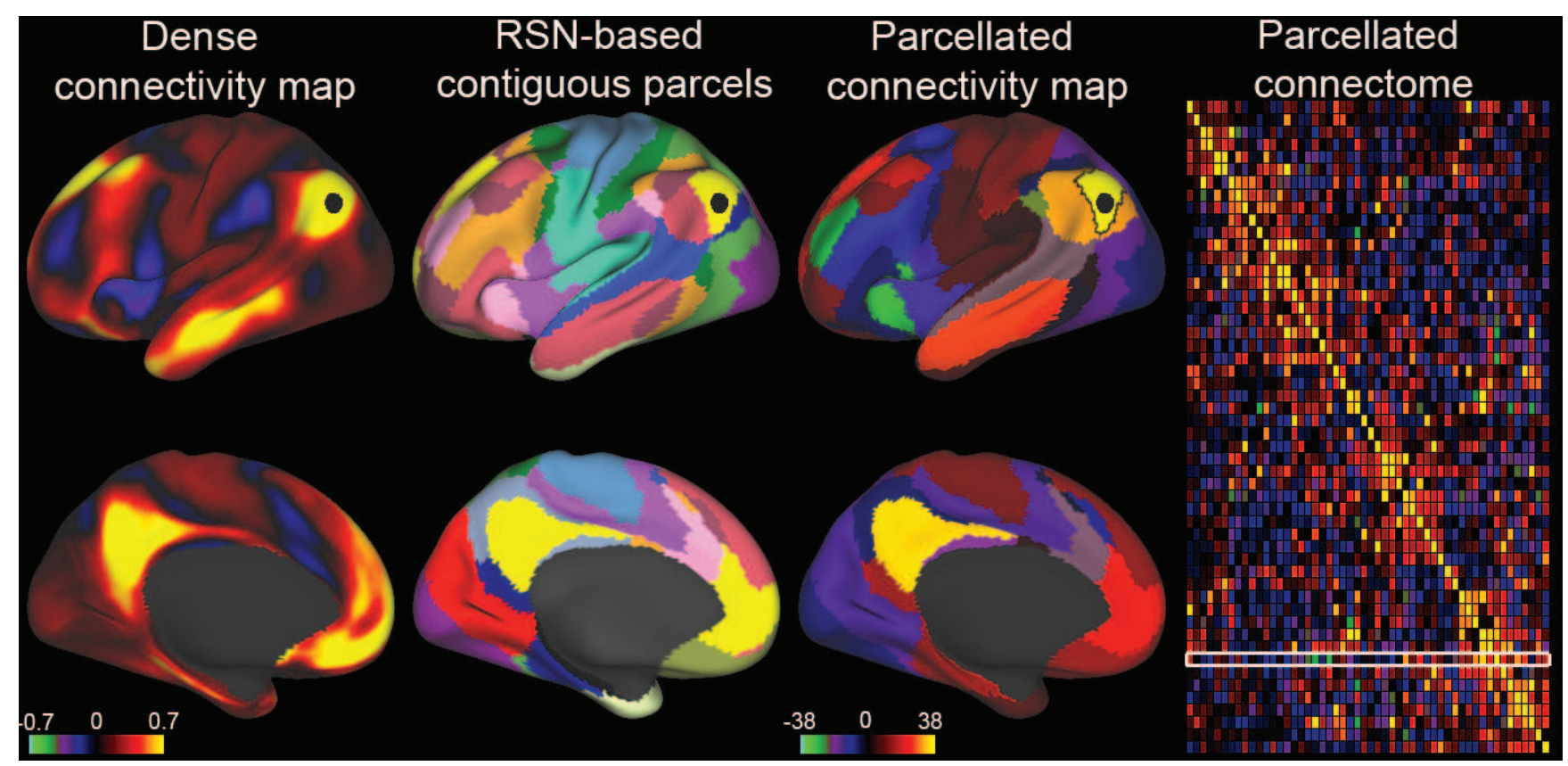

Figure 6. Resting-state functional connectivity from the Human Connectome Project (HCP) data. Columns 1, 2 and 3: functional connectivity from a "seed" in parietal cortex (black disk), based on a group average of 468 subjects; 52 left-hemisphere contiguous parcels from the resting-state networks (RSN); parcellated connectivity map for a default-mode network parcel containing the selected seed, based on 447 HCP subjects. Column 4: group-average parcellated connectome showing relative connection strength between regions. Image courtesy of the HCP consortium - http://humanconnectome.org.

National Science Foundation along with the National Institutes of Health and the Defense Advanced Research Projects Agency and includes private partners (34). It holds great promise for addressing fundamental questions about healthy brain function, advancing treatments for brain disorders or traumatic brain injury, and for generating brain-inspired "smart" technologies to meet our future needs as a society. BRAIN Initiative is committing approximately $\$ 200$ million in 2015 . It will sponsor studies related to quantitative and predictive theories of brain function, development of innovative technologies for understand brain function and treating brain disorders. It will help the development of cyber tools and standards for data acquisition, analysis and integration, foster multi-scale and multimodal modeling to relate dynamic brain activity to cognition and behavior and at the same time apply comparative analyses across species. Taken together these important scientific initiatives and modern imaging technology will bring us closer to understanding the mysteries of the central nervous system and help us understand and cure neurological diseases.
As it can be seen by this brief synopsis, the research on the brain has gone through a remarkable historic development and transformation. This journey has been lead by great human individuals many of whom have not been mentioned here in the interest of space. There are countless many who deserve mention. These renaissance men and women left their illuminating mark on the progress of neuroscience. Many of their original ideas, concepts and beliefs have endured the test of time. Knowledge of the anatomy and function of the nervous system are the pillars of contemporary clinical neurology. While the long itinerary of this knowledge dates back to antiquity, current studies on the amazing and mysteriously beautiful human brain is perhaps the most dynamic field of modern human endeavor.

\section{REFERENCES}

1. Verano O, Finger S. Ancient trepanation. In: Finger S, Boller K, Tyler L, editors, Handbook of Clinical Neurology, Vol. 95, History of Neurology, Elsevier, 2010. 
2. Brandt-Rauf P, Brandt-Rauf S. History of occupational medicine: relevance of Imhotep and the Edwin Smith papyrus, Br J Med 1987; 44: 68-70.

3. York G, Steinberg D. Neurology in ancient Egypt. In: Finger F, Boller K, Tyler L, editors, Handbook of Clinical Neurology, Vol. 95, History of Neurology, Elsevier 2010.

4. Gross C. From Imhotep to Hubel and Wiesel. The story of visual cortex. In: Cerebral Cortex, vol. 12, Rockland et al., editors, Plenum Press, NY, 1997.

5. Karenberg A, The Greco-Roman world, In: Finger F, Boller K, Tyler L, editors, Handbook of Clinical Neurology, Vol. 95, History of Neurology, Elsevier 2010.

6. Crivellato E, Ribatti D. History of Neuroscience: Soul, mind, brain: Greek philosophy and the birth of neuroscience. Brain Res Bull 2007; 71: 327-336.

7. Adrian W. Herophilus, Erasistratus, and the birth of neuroscience. Lancet 1999; 354: 1719-1720.

8. Pasipoularides A. Galen, father of systematic medicine. An essay on the evolution of modern medicine and cardiology. Int J Cardiol 2014; 172: 47-58.

9. Russell G. After Galen: Late Antiquity and the Islamic world. In: Finger F, Boller K, Tyler L, editors, Handbook of Clinical Neurology, Vol. 95, History of Neurology, Elsevier 2010.

10. Schalick III, W. Neurological conditions in the European Middle Ages. In: Finger F, Boller K, Tyler L, editors, Handbook of Clinical Neurology, Vol. 95, History of Neurology, Elsevier 2010.

11. Kickhofel, E. Sine ars scientia nihil est: Leonardo da Vinci and beyond. Epilepsy Behav 2009; 14: 5-11.

12. Pevsner J. Leonardo da Vinci's contributions to neuroscience. Trends Neurosci 2002; 25: 217-220.

13. Bentivoglio $M$, Mazzarello $P$. The anatomical foundations of clinical neurology. In: Finger F, Boller K, Tyler L, editors, Handbook of Clinical Neurology, Vol. 95, History of Neurology, Elsevier 2010.

14. Ione A. Visual images and neurological illustration, In: Finger F, Boller K, Tyler L, editors, Handbook of Clinical Neurology, Vol. 95, History of Neurology, Elsevier 2010.

15. Tubbs R, Salter E. Charles Estienne (Carolus Stephanus) (ca.1504-1564): Physician and Anatomist. Clin Anat 2006; 19: 4-7.

16. Roberts M. Human dissection - From Galen to the great revelations of Andreas Vesalius. http://brainblogger. com/2011/08/20/human-dissection-from-galen-to-thegreat-revelations-of-andreas-vesalius/.
17. Linden D. Five hundred years of brain images. Arch Neurol 2002; 59: 308-313.

18. Abbot A. The man who bared the brain. Nature 2015; 521: 160 .

19. Isler $H$. The development of neurology and the neurological sciences in the 17th century, In: Finger F. Boller K, Tyler L. editors.Handbook of Clinical Neurology, Vol. 95 History of Neurology. Elsevier, 2010.

20. Mazzarello P, Garbarino C, Calligaro, A. How Camillo Golgi became "the Golgi". FEBS Lett 2009; 583: 3732-3737.

21. Lopez-Munoz F, Boya J, Cecilio, A. Neuron theory, the cornerstone of neuroscience, on the centenary of the Nobel Prize award to Santiago Ramon y Cajal. Brain Res Bull 2006; 70: 391-405.

22. Levi-Montalcini R. The nerve growth factor: 35 years later. Science 1987; 237: 1154-1162.

23. Chaldakov GN, Aloe L. Homage to Rita Levi-Montalcini, the Queen of modern neuroscience. Biomed Rev 2012; 23: 1-7.

24. Roxo M. Franceschini P, Zubaran C, Kleber F, Sander J. The limbic system conception and its historical evolution. The Scientific World Journal 2011; 11: 2428-2441,

25. Lazar R, Mohr J. Revisiting the Contributions of Paul Broca to the Study of Aphasia. Neuropsychol Rev 2011; 21:236-239.

26. Zilles K, Amunts K. Centenary of Brodmann's map conception and fate, Nature Reviews, Neuroscience 2010; 11: 139-145.

27. Brodmann K. Vergleichende Lokalisationslehre der Großhirnrinde in ihren Prinzipien dargestellt auf Grund des Zellenbaues, Barth, Leipzig, 1909.

28. Ward, Z. Letter to the editor: Reexamining Penfield's homunculus. J History Neurosci 2014; 23: 198-203.

29. Raichle M. Positron emission tomography. Ann Rev Neurosci 1983; 6: 249-267.

30. Raichle $M$. The origins of functional brain imaging in humans, In: Finger F, Boller K, Tyler L. editors, Handbook of Clinical Neurology, Vol. 95, History of Neurology, Elsevier, 2010.

31. Lichtman J, Sanes J, Livet J. A technicolour approach to the connectome. Nat Rev Neurosci 2008; 9: 417-422.

32. https://www.youtube.com/watch?v=F37kuXObIBU).

33. http://www.humanconnectome.org/.

34. http://braininitiative.nih.gov/. 